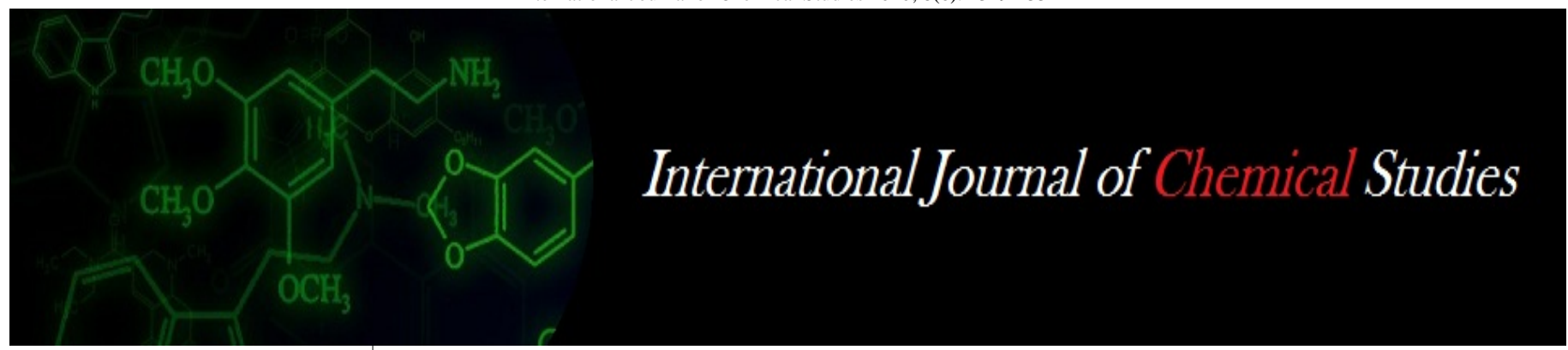

P-ISSN: 2349-8528

E-ISSN: 2321-4902

www.chemijournal.com

IJCS 2020; 8(6): 1329-1332

(C) 2020 IJCS

Received: 14-09-2020

Accepted: 18-10-2020

\section{SB Jadhav}

Assistant Professor, Department of IDE, CAET, VNMKV,

Parbhani, Maharashtra, India

UM Khodke

Associate Dean and Principal, College of Agricultural

Engineering and Technology,

VNMKV, Parbhani,

Maharashtra, India

\section{Soil moisture distribution studies under drip irrigation in soils of Marathwada (M.S.)}

\author{
SB Jadhav and UM Khodke
}

DOI: https://doi.org/10.22271/chemi.2020.v8.i6s.10944

\begin{abstract}
A field experiment was conducted during 2017-2018 at AICRP on Water Management, VNMKV, Parbhani to study the effect of drip irrigation supplies on soil moisture distribution, yield of cabbage under different irrigation schedules and fertigation levels. Drip method with alternate day irrigation was adopted for all the plots with five irrigation levels as main plot viz., 0.4 ETc $\left(\mathrm{I}_{1}\right), 0.6$ ETc $\left(\mathrm{I}_{2}\right), 0.8$ ETc $\left(\mathrm{I}_{3}\right), 1.0$ ETc $\left(\mathrm{I}_{4}\right)$ and 1.2 ETc $\left(\mathrm{I}_{5}\right)$. Fertigation levels were $50 \%\left(\mathrm{~F}_{1}\right), 75 \%\left(\mathrm{~F}_{2}\right)$ and $100 \%\left(\mathrm{~F}_{3}\right)$ of recommended dose of fertilizers (120:60:60; $\mathrm{N}: \mathrm{P}_{2} \mathrm{O}_{5}: \mathrm{K}_{2} \mathrm{O} \mathrm{kg} \mathrm{ha-1}$ ) with eight splits during crop growth period. Under all irrigation depths the moisture content in surface soil layer $(0-15 \mathrm{~cm})$ was higher and lie between 32 to 38 per cent throughout the irrigation cycle whereas in 15-30 cm layer it is in between 30 to 36 per cent. Increase in irrigation level was found to increase the moisture content in both the layers. The moisture content below the emitter was always higher and it was found to decrease horizontally away from the emitter.
\end{abstract}

Keywords: Soil moisture, drip irrigation, Maharashtra

\section{Introduction}

A field experiment was conducted during 2017-2018 at AICRP on Water Management, VNMKV, Parbhani to study the effect of drip irrigation supplies on soil moisture distribution, yield of cabbage under different irrigation schedules and fertigation levels. Drip method with alternate day irrigation was adopted for all the plots with five irrigation levels as main plot viz., 0.4 ETc $\left(\mathrm{I}_{1}\right)$, 0.6 ETc $\left(\mathrm{I}_{2}\right), 0.8$ ETc $\left(\mathrm{I}_{3}\right), 1.0$ ETc $\left(\mathrm{I}_{4}\right)$ and 1.2 ETc $\left(\mathrm{I}_{5}\right)$. Fertigation levels were $50 \%\left(\mathrm{~F}_{1}\right), 75 \%\left(\mathrm{~F}_{2}\right)$ and $100 \%\left(\mathrm{~F}_{3}\right)$ of recommended dose of fertilizers $(120: 60: 60 ; \mathrm{N}$ : $\mathrm{P}_{2} \mathrm{O}_{5}: \mathrm{K}_{2} \mathrm{O} \mathrm{kg} \mathrm{ha}^{-1}$ ) with eight splits during crop growth period. The wetting pattern of soil under trickle (drip) irrigation is governed by soil texture, structure, initial water content, emitter spacing, discharge rate and irrigation frequency. For efficient management of trickle irrigation moisture distribution plays an important role. The degree of soil wetted volume in an irrigation system determines the ample amount of water required to wet the root zone. This article helps in understanding moisture distribution for drip irrigation under soil conditions of Marathwada region.

\section{Material and Methods}

In order to assess the changes in soil water status, soil moisture was measured in 0-15 and 1530 layers of soil profile. For monitoring the soil moisture distribution an irrigation cycle of 12 days (62 to 72 DAP) during the growth period of cabbage was selected. The soil samples were collected from each plot with the help of screw auger at a grid of $15 \mathrm{~cm}$ vertically $(0$ to $30 \mathrm{~cm})$ below emitter and horizontally $(0$ to $30 \mathrm{~cm}$ ) from the location of emitter. Initial and final oven dry weights of soil samples were measured using digital sensitive electronic balance. The soil samples were kept in hot air oven at $105^{\circ} \mathrm{C}$ for 24 hrs to determine the moisture content by gravimetric method. The soil of the experimental plot was deep black vertisol.

\section{Results and Discussion}

In order to assess the depth and time variation of soil moisture under different irrigation depths, an irrigation cycle of 12 days (62 to 73 DAP) was selected during the crop growing season and soil moisture was monitored in $0-15$ and $15-30 \mathrm{~cm}$ soil layers. The soil moisture presented in this section is the average values of measured soil moisture under different

\section{SB Jadhav}

Assistant Professor, Department

of IDE, CAET, VNMKV,

Parbhani, Maharashtra, India 
irrigation levels during this period 17 March to 28 March 2017(62 to 73 DAP), the plots were irrigated six times with drip irrigation.

The moisture content was measured at 0,15 and $30 \mathrm{~cm}$ radial distance away from the position of emitter. The data on measured moisture content at different radial distances from the emitter and vertical distances below soil surface under different irrigation levels/ depths is shown in Table 1 to Table 3.

Table 1: Soil moisture contents measured below the emitter

\begin{tabular}{|c|c|c|c|c|c|c|}
\hline Day of irrigation cycle & Depth (cm) & $\mathbf{I}_{\mathbf{1}}$ & $\mathbf{I}_{\mathbf{2}}$ & $\mathbf{I}_{\mathbf{3}}$ & $\mathbf{I}_{\mathbf{4}}$ & $\mathbf{I}_{\mathbf{5}}$ \\
\hline 1 & 15 & 33.23 & 34.26 & 34.98 & 35.29 & 36.05 \\
\hline 2 & 30 & 31.28 & 32.29 & 33.56 & 33.94 & 34.81 \\
\hline & 15 & 34.02 & 35.25 & 36.58 & 36.98 & 37.89 \\
\hline 3 & 30 & 32.25 & 33.56 & 34.87 & 35.78 & 35.98 \\
\hline & 15 & 33.69 & 34.58 & 35.25 & 35.99 & 36.28 \\
\hline 4 & 30 & 31.28 & 32.59 & 33.58 & 34.57 & 35.21 \\
\hline & 15 & 34.21 & 35.25 & 36.29 & 36.99 & 37.58 \\
\hline 5 & 30 & 31.69 & 32.19 & 33.57 & 34.56 & 36.11 \\
\hline & 15 & 32.99 & 32.29 & 33.69 & 34.28 & 35.87 \\
\hline 6 & 30 & 31.74 & 32.16 & 32.97 & 33.58 & 32.98 \\
\hline & 15 & 33.69 & 33.28 & 34.58 & 35.26 & 36.96 \\
\hline 7 & 30 & 32.18 & 32.67 & 32.87 & 33.58 & 34.57 \\
\hline & 15 & 34.56 & 32.58 & 35.69 & 36.87 & 36.96 \\
\hline \hline & 30 & 31.56 & 32.11 & 33.25 & 34.53 & 35.21 \\
\hline & 15 & 34.29 & 35.26 & 36.36 & 36.98 & 37.23 \\
\hline & 30 & 32.58 & 33.25 & 34.27 & 34.99 & 36.09 \\
\hline 10 & 15 & 32.98 & 33.58 & 33.69 & 34.59 & 36.69 \\
\hline & 30 & 30.58 & 31.28 & 31.88 & 32.45 & 33.27 \\
\hline 11 & 15 & 33.54 & 34.23 & 34.99 & 35.68 & 36.59 \\
\hline & 30 & 31.97 & 32.85 & 33.54 & 33.91 & 34.29 \\
\hline 12 & 15 & 33.68 & 34.56 & 36.56 & 37.12 & 38.5 \\
\hline & 30 & 31.67 & 32.65 & 33.49 & 34.38 & 36.05 \\
\hline & 15 & 34.25 & 35.29 & 36.68 & 37.54 & 37.99 \\
\hline & 30 & 33.01 & 33.87 & 34.09 & 35.28 & 35.89 \\
\hline
\end{tabular}

Table 2: Soil moisture contents measured at $15 \mathrm{~cm}$ away horizontal distance from emitter

\begin{tabular}{|c|c|c|c|c|c|c|}
\hline Day of irrigation cycle & Depth (cm) & $\mathbf{I}_{\mathbf{1}}$ & $\mathbf{I}_{\mathbf{2}}$ & $\mathbf{I}_{\mathbf{3}}$ & $\mathbf{I}_{\mathbf{4}}$ & $\mathbf{I}_{\mathbf{5}}$ \\
\hline 1 & 15 & 31.25 & 32.25 & 32.98 & 33.39 & 34.58 \\
\hline 2 & 30 & 29.36 & 30.29 & 31.84 & 32.08 & 33.29 \\
\hline & 15 & 32.57 & 33.58 & 34.58 & 34.98 & 35.28 \\
\hline 3 & 30 & 30.58 & 31.64 & 32.74 & 33.54 & 34.29 \\
\hline & 15 & 31.66 & 32.58 & 33.69 & 34.25 & 35.87 \\
\hline 4 & 30 & 29.54 & 29.69 & 30.58 & 31.28 & 33.09 \\
\hline & 15 & 32.29 & 33.87 & 34.58 & 35.87 & 36.12 \\
\hline 5 & 30 & 30.11 & 31.25 & 32.45 & 33.69 & 34.58 \\
\hline & 15 & 30.25 & 31.28 & 32.25 & 33.28 & 34.56 \\
\hline 6 & 30 & 29.05 & 30.24 & 31.58 & 32.12 & 33.57 \\
\hline & 15 & 31.59 & 32.01 & 33.11 & 33.98 & 34.25 \\
\hline 7 & 30 & 30.29 & 31.29 & 31.99 & 33.21 & 34.01 \\
\hline 8 & 15 & 31.68 & 31.97 & 33.18 & 34.29 & 35.27 \\
\hline & 30 & 29.54 & 30.59 & 31.56 & 32.58 & 33.44 \\
\hline 9 & 15 & 32.22 & 33.65 & 34.27 & 34.99 & 35.97 \\
\hline & 30 & 30.59 & 32.05 & 33.68 & 33.65 & 34.85 \\
\hline 10 & 15 & 28.56 & 29.68 & 31.59 & 32.58 & 33.96 \\
\hline & 30 & 27.36 & 28.25 & 29.66 & 31.25 & 31.89 \\
\hline 11 & 15 & 30.65 & 31.57 & 32.79 & 33.91 & 34.84 \\
\hline & 30 & 28.65 & 29.63 & 31.09 & 32.12 & 33.08 \\
\hline 12 & 15 & 30.58 & 31.94 & 33.28 & 34.58 & 35.77 \\
\hline & 30 & 29.26 & 30.59 & 31.28 & 32.88 & 34.65 \\
\hline & 15 & 32.57 & 33.59 & 34.44 & 35.46 & 36.58 \\
\hline & 30 & 30.28 & 31.22 & 32.69 & 33.78 & 34.05 \\
\hline
\end{tabular}

Table 3: Soil moisture contents measured at $30 \mathrm{~cm}$ away horizontal distance from emitter

\begin{tabular}{|c|c|c|c|c|c|c|}
\hline Day of irrigation cycle & Depth (cm) & $\mathbf{I}_{\mathbf{1}}$ & $\mathbf{I}_{\mathbf{2}}$ & $\mathbf{I}_{\mathbf{3}}$ & $\mathbf{I}_{\mathbf{4}}$ & $\mathbf{I}_{\mathbf{5}}$ \\
\hline 1 & 15 & 24.22 & 25.51 & 26.35 & 26.92 & 27.76 \\
\hline 2 & 30 & 22.88 & 23.41 & 24.21 & 24.67 & 25.34 \\
\hline & 15 & 25.22 & 25.89 & 26.35 & 27.89 & 28.23 \\
\hline 3 & 30 & 22.02 & 22.56 & 23.14 & 23.87 & 24.76 \\
\hline
\end{tabular}




\begin{tabular}{|c|c|c|c|c|c|c|}
\hline & 30 & 19.24 & 20.35 & 20.99 & 21.78 & 22.77 \\
\hline 4 & 15 & 25.02 & 25.86 & 26.43 & 27.05 & 27.66 \\
\hline & 30 & 21.35 & 22.57 & 23.85 & 24.65 & 25.51 \\
\hline 5 & 15 & 24.76 & 25.53 & 25.99 & 26.76 & 27.62 \\
\hline 6 & 30 & 19.34 & 21.34 & 22.89 & 23.45 & 24.38 \\
\hline & 15 & 23.65 & 24.24 & 25.31 & 26.03 & 26.86 \\
\hline 7 & 30 & 19.36 & 20.43 & 22.05 & 23.98 & 24.05 \\
\hline & 15 & 24.54 & 25.75 & 25.98 & 26.52 & 27.12 \\
\hline 8 & 30 & 21.43 & 22.45 & 23.06 & 23.87 & 24.23 \\
\hline & 15 & 23.54 & 24.44 & 25.01 & 26.21 & 26.98 \\
\hline & 30 & 18.68 & 19.56 & 21.76 & 22.65 & 23.98 \\
\hline & 15 & 24.23 & 24.99 & 25.61 & 26.63 & 27.89 \\
\hline 10 & 30 & 19.24 & 21.32 & 22.87 & 23.14 & 24.87 \\
\hline 11 & 15 & 22.34 & 23.45 & 24.11 & 25.56 & 26.87 \\
\hline & 30 & 17.36 & 18.36 & 20.76 & 21.89 & 22.85 \\
\hline 12 & 15 & 24.12 & 24.97 & 25.67 & 25.99 & 26.78 \\
\hline & 30 & 19.25 & 20.57 & 22.43 & 22.97 & 24.05 \\
\hline & 15 & 22.76 & 23.56 & 24.21 & 24.98 & 25.87 \\
\hline & 30 & 18.35 & 19.38 & 20.42 & 21.11 & 22.04 \\
\hline
\end{tabular}

The temporal variation of soil moisture in different irrigation depths is presented through Fig. 1 to Fig. 3.
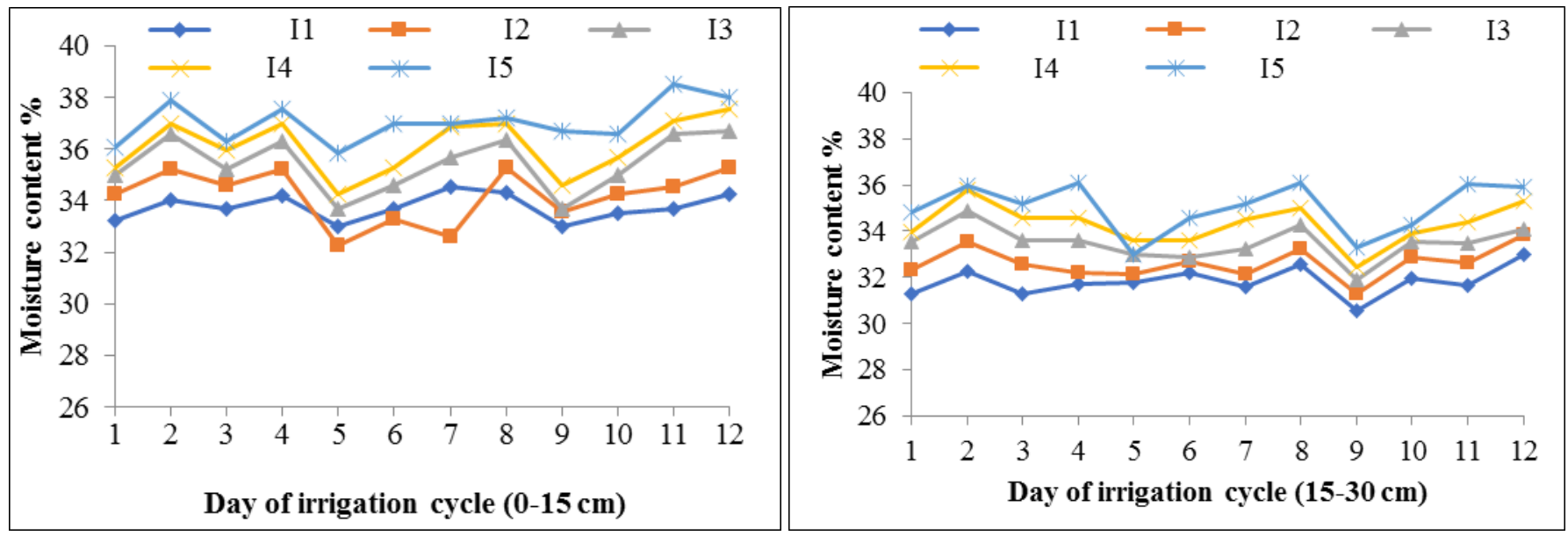

Fig 1: Moisture distributions under different irrigation levels below emitter

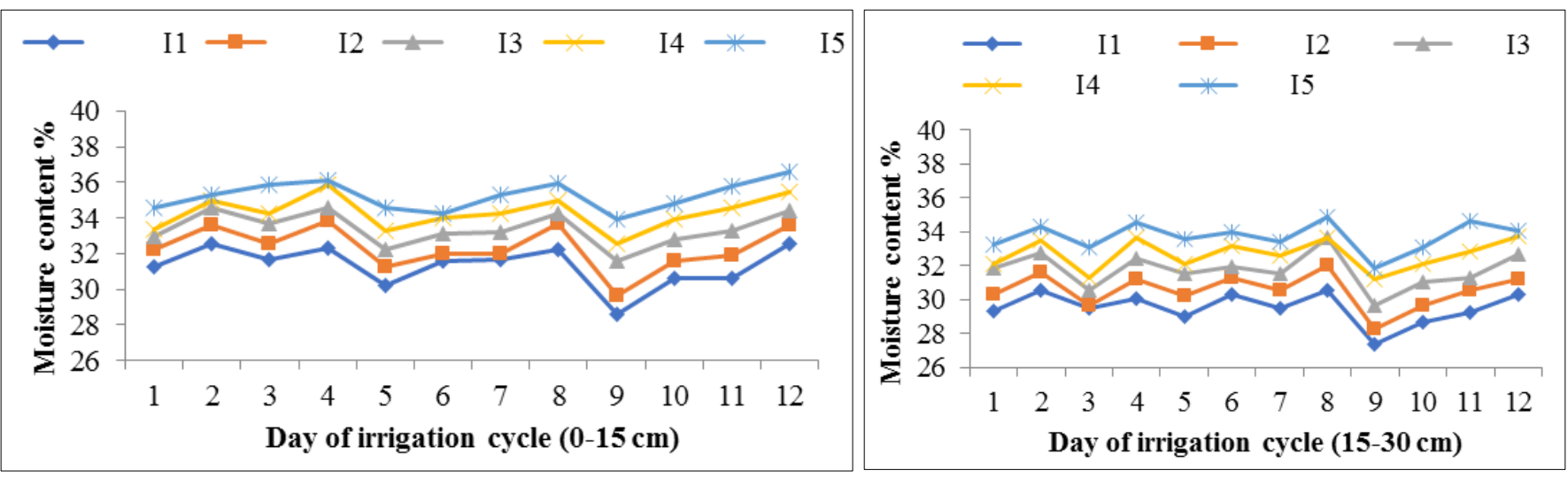

Fig 2: Moisture distributions under different irrigation levels at $15 \mathrm{~cm}$ away horizontal distance from emitter 

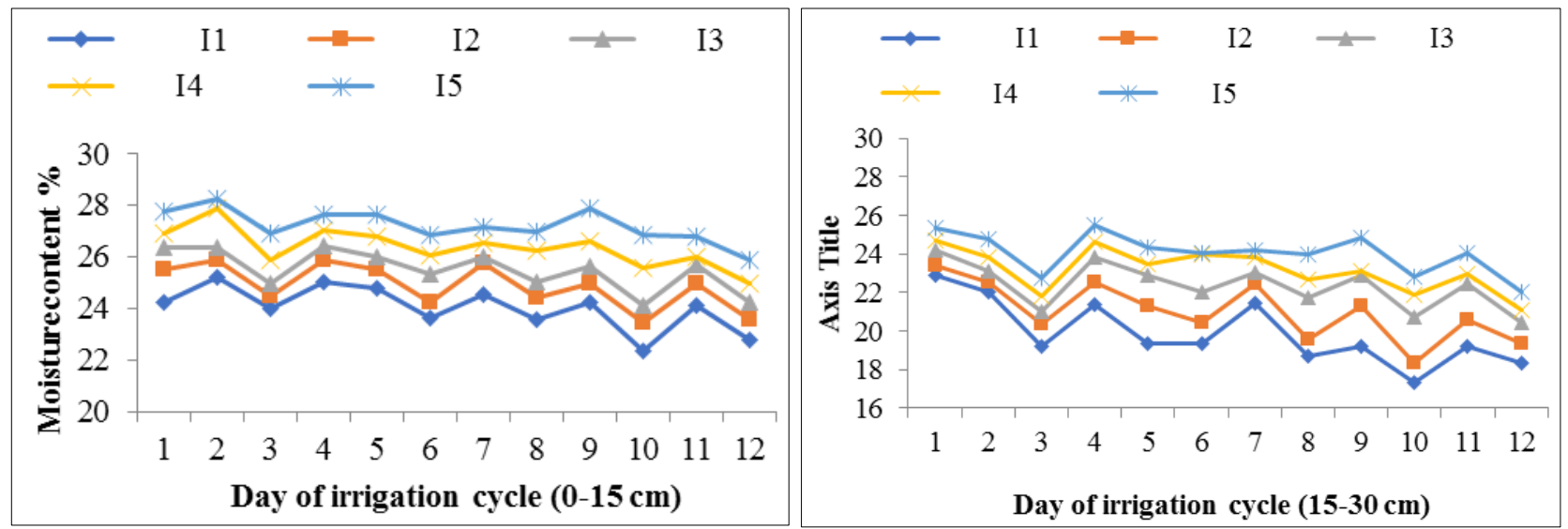

Fig 3: Moisture distributions under different irrigation levels at $30 \mathrm{~cm}$ away horizontal distance from emitter

The figures revealed that in general, the soil moisture experienced a cyclic temporal variation following the irrigation event. Barring few exceptions, the amplitude of this cyclic variation was slightly higher in upper $(0-15 \mathrm{~cm})$ soil layer than the lower $(15-30 \mathrm{~cm})$ soil layer. Fig. 1 shows moisture content under different irrigation depths measured below emitter. Under all drip irrigation depths, the moisture content in surface soil layer $(0-15 \mathrm{~cm})$ lie between 32 to $38 \%$ throughout the irrigation cycle whereas the moisture content in $15-30 \mathrm{~cm}$ layer is in between 30 to $36 \%$. With the increase in depth of drip irrigation the moisture content in both the layers is found to be increased.

The moisture content under different irrigation levels measured at $15 \mathrm{~cm}$ away from the emitter is depicted in Fig. 2. Figure shows that, under all irrigation levels the moisture content in surface soil layer $(0-15 \mathrm{~cm})$ lie between 28 to $36 \%$ whereas the moisture content in 15-30 cm layer is in between 27 to $34 \%$. The moisture contents at $15 \mathrm{~cm}$ away from the emitter are slightly lower (Fig. 2) than the moisture content below emitter (Fig. 1) for particular irrigation level. The cyclic variation of moisture content was more pronounced in upper layer $(0-15 \mathrm{~cm})$ than the lower layer $(15-30 \mathrm{~cm})$.

The moisture content under different irrigation strategies measured at $30 \mathrm{~cm}$ away from the emitter in both the soil layers is depicted in Fig. 3. Under all irrigation levels the moisture content in surface soil layer $(0-15 \mathrm{~cm})$ lie between 22 to $27 \%$ whereas the moisture content in $15-30 \mathrm{~cm}$ layer is in between 17 to $25 \%$. This indicate that in both the soil layers moisture contents are lower than those shown in Fig. 1 and 2 measured below emitter and at $15 \mathrm{~cm}$ away from emitter, respectively. This clearly indicates that the moisture content in both soil layers decreases with increase in the horizontal distance from the emitter. The moisture contents at $30 \mathrm{~cm}$ away from the emitter are also around field capacity which is required for better growth of cabbage.

\section{Conclusion}

Under all irrigation depths the moisture content in surface soil layer $(0-15 \mathrm{~cm})$ was higher and lie between 32 to 38 per cent throughout the irrigation cycle whereas in 15-30 cm layer it is in between 30 to 36 per cent. Increase in irrigation level was found to increase the moisture content in both the layers. The moisture content below the emitter was always higher and it was found to decrease horizontally away from the emitter.

\section{References}

1. Mallikarjun Reddy, Ayyanagowdar MS, Nemichandrappa M. Characterize the Moisture Distribution Pattern in Drip Irrigation under Sandy Loam
Soil. Int. J Curr. Microbiol. App. Sci. 2018;7(04):29152923.

2. Mirjat MS, Mirjat MU, Chandio FA. Water distribution, distribution uniformity and application efficiency of locally made emitters used in a trickle subunit. Pakistan. Journal of Agriculture, Agricultural Engineering and Vetnary Sciences 2010;26(1):1-15.

3. Panigrahi B, Roy DP, Panda SN. Water use and yield response of tomato as influenced by drip and furrow irrigation. International Agricultural Engineering Journal 2010;19(1):19-30.

4. Ramah K, Santhi P, Thiyagarajan G. Moisture distribution pattern in drip irrigated maize based cropping system. Madras Agriculture Journal 2011;98(1-3):51-55.

5. Shrivastava P, Rajput GS, Nayak S. Soil moisture distribution as influenced by drip irrigation supply and planting pattern in heavy soils of Madhya Pradesh. Journal of Agricultural Technology 2011;7(4):11771186.

6. Vijayakumar G, Tamilmani D, Selvaraj PK, Ramaswamy K. (). Moisture movement and nitrogen distribution in onion under drip fertigation in sandy loam soil. Indian Journal of Soil Conservation 2011;39(1):37-43. 